\title{
PENGARUH PEMBELAJARAN MATEMATIKA REALISTIK TERHADAP KEMAMPUAN MATEMATIS SISWA (DITINJAU DARI KEMAMPUAN REPRESENTASI DAN KOMUNIKASI)
}

\author{
Hidayatul Purnama Ariyanti \\ (Pendidikan Matematika, Fakultas Keguruan dan Ilmu Pendidikan, Universitas PGRI Adi Buana Surabaya) \\ rhyrhyzhaa@gmail.com
}

\begin{abstract}
This research is motivated by the low mathematical ability of students seen in the test results Programme for International Student Assessment (PISA) in 2012. The ability of mathematics not only be based on the ability of understanding only, but there are also other capabilities that factor into the level of mathematical ability of students, among others, representation and communication capabilities. So to overcome this use realistic mathematics learning. Formulation of the problem in this research is "Is there any realistic mathematics education effect on the ability of students' mathematical representation and communication?". The goal was to determine the effect of realistic mathematics learning of the mathematical ability of students' representation and communication. The method used is Posttest-Only Control Design which will give treatment to the realistic mathematics learning experiment class and conventional learning to control class. After treatment, given posttes to measure its influence in the ability of students' mathematical representation and communication. The research instrument in the form of tests which contains the indicator variables. Subjects in this study were 32 students of the control class and 32 students for the experimental class. For data analysis used the t-test previously conducted pre-requisite test the normality and homogeneity test. In this study, $\mathrm{H}_{0}$ reads No realistic mathematics education effect on the ability of students' mathematical representation and communication. And $\mathrm{H}_{1}$ reads no realistic mathematics education effect on the ability of students' mathematical representation and communication. The results show the ability of the student representation is obtained and the communication skills of students obtained which showed that $\mathrm{H}_{0}$ refused on both. It can be concluded that the realistic mathematics instruction affect the ability of students' mathematical representation and communication.
\end{abstract}

Keywords: Realistic Mathematics Education, Communication Skills, Representation Skills.

\section{PENDAHULUAN}

Ruseffendi (dalam Baroroh, 2010 : 9) mengatakan bahwa kegunaan matematika adalah antara lain dapat menyelesaikan soal-soal dan berkomunikasi seharihari, meningkatkan kemampuan berpikir logis, tepat, dan pemahaman ruang. Namun pada kenyataannya peringkat kemampuan matematika siswa di Indonesia masih sangat rendah. Hasil tes Programme for International Student Assesment (PISA) pada tahun 2012, sebuah studi yang dilakukan oleh OECD (Organisation for Economic Co-operation and Development) yang merupakan gabungan tes matematika, sains, dan membaca siswa berumur 15 tahun, Indonesia menempati peringkat 64 dari 65 negara yang berpartisipasi (Rima dalam blogs.itb.ac.id/appledore/2014/02/18/32).

PISA tidak hanya terfokus pada kemampuan berhitung saja namun juga terfokus pada kemampuan siswa dalam menganalisa, memberikan alasan, dan menyampaikan ide secara efektif, merumuskan, memecahkan, dan menginterpretasi masalah-masalah matematika dalam berbagai bentuk dan situasi. PISA menuntut siswa untuk menggunakan kemampuankemampuan yang relevan dalam konteks yang tidak terlalu terstruktur, sehingga petunjuk tidak begitu jelas bagi siswa. Salah satu indikator yang menyebabkan hasil PISA Indonesia buruk menurut Pranoto ( http://www.slideshare.net/y0r/un-matematikamenyiapkan-anak-menjadi-kuli-nirnalar) adalah siswa kita lemah dalam memodelkan situasi nyata ke masalah matematika dan menafsirkan solusi matematika ke situasi nyata. Ini artinya siswa belum mencapai seluruh standar kemampuan matematis yang menurut National Council of Teachers of Mathematics (NCTM) (dalam Simanjuntak, 2014 : 6), lima standar kemampuan matematis yaitu terdiri atas pemecahan masalah (problem solving), penalaran dan bukti (reasoning and proof), komunikasi (communication), 
Hidayatul Purnama Ariyanti : Pengaruh Pembelajaran Matematika Realistik Terhadap Kemampuan Matematis Siswa (Ditinjau Dari Kemampuan Representasi Dan Komunikasi)

koneksi (connections), dan representasi (representation).

Dua kemampuan matematis yang saling berkaitan dan berpengaruh dalam kemapuan matematis siswa adalah kemampuan komunikasi dan representasi. Siswa yang sudah mempunyai kemampuan pemahaman matematis dituntut juga untuk bisa mengkomunikasikannya, agar pemahamannya bisa dimanfaatkan oleh orang lain. Dengan kemampuan komunikasi matematis siswa juga bisa memanfaatkan konsep-konsep matematika yang sudah dipahami orang lain. Sedangkan representasi sendiri merupakan salah satu kunci keterampilan komunikasi matematis. Secara tidak langsung, hal ini mengindikasikan bahwa proses pembelajaran yang menekankan pada kemampuan representasi akan melatih siswa dalam komunikasi matematis.

Pembelajaran Matematika Realistik (PMR) merupakan salah satu pembelajaran yang dapat digunakan untuk meningkatkan kemampuan representasi dan komunikasi matematis. Beberapa karakteristik dari PMR diantaranya adalah kegiatan interaktif. Siswa diberi kesempatan menyampaikan ideide dan berdiskusi sesama siswa serta interaksi dengan guru yang dapat mengasah kemampuan komunikasi matematis siswa. Selain itu PMR menggunakan instrumen vertikal berupa model, skema, diagram ataupun simbol (Aditya, 2014: 5). Hal itu dapat diartikan sebagai menerjemahkan suatu masalah dalam bentuk matematis berupa gambar, simbol maupun persamaan matematis yang mana hal ini merupakan bentuk dari representasi eksternal.

Melihat paparan di atas, penelitian ini ingin menjawab permasalahan, adakah pengaruh pembelajaran matematika realistik terhadap kemampuan representasi dan komunikasi matematis siswa? Dengan demikian, penelitian ini bertujuan untuk mengetahui pengaruh Pembelajaran Matematika Realistik terhadap kemampuan representasi dan komunikasi siswa. Penelitian ini diharapkan dapat bermanfaat bagi guru matematika agar lebih variatif dalam melaksanakan pembelajaran matematika.

\section{METODE PENELITIAN}

Penelitian ini menggunakan metode eksperimen dengan menggunakan desain Posttest-Only Control Design (Sugiyono, 2010 : 116) yang bertujuan untuk mengetahui signifikansi pengaruh pembelajaran matematika realistik terhadap kemampuan representasi dan komunikasi siswa. pengambilan sampel penelitian dengan menggunakan teknik non probability sampling dengan metode accidental sampling yakni pengambilan sampel didasarkan pada kenyataan bahwa hanya sampel itulah yang tersedia untuk diteliti. Sampel diambil berdasarkan kelas yang telah diberikan sekolah kepada peneliti kemudian dijadikan kelompok kontrol dan kelompok eksperimen. Kelas VII F sebagai kelompok eksperimen sebanyak 32 siswa dan kelas VII H sebagai kelas kontrol sebanyak 32 siswa.

Penelitian ini menggunakan instrumen penelitian berupa tes kemampuan representasi dan komunikasi siswa yang disusun berdasarkan indikator masingmasing kemampuan. Tes hanya dilakukan setelah pemberian perlakuan pembelajaran matematika realistik pada kelas eksperimen dan pembelajaran konvensional pada kelas kontrol. Teknik analisis data menggunakan uji-t setelah dilakukan uji asumsi normalitas dan uji homogenitas variansi.

\section{HASIL PENELITIAN}

Hasil penelitian ini dipaparkan dalam dua bagian, yakni hasil kemampuan representasi matematis dan hasil kemampuan komunikasi matematis.

Kemampuan Representasi Matematis. Hasil uji normalitas kelas eksperimen matematis, diperoleh $\chi_{\text {hitung }}^{2}(9,5970)<\chi_{\text {tabel }}^{2}(11,07)$ yang berarti data 
tersebut berdistribusi normal. Pada kelas kontrol juga berdistribusi normal

dengan $\chi_{\text {hitung }}^{2}(4,7853)<\chi_{\text {tabel }}^{2}(11,07)$. Untuk uji homogenitas diperoleh $F_{\text {hitung }}(1,799) \leq F_{\text {tabel }}(1,822)$, artinya data yang diperoleh variansinya homogen.

Berikut ini akan disajikan tabel sumber data kemampuan representasi matematis siswa.

Tabel 1: Sumber Data Kemampuan Representasi

\begin{tabular}{|c|c|c|}
\hline Sumber variasi & $\begin{array}{c}\text { Kelas } \\
\text { Eksperimen }\end{array}$ & $\begin{array}{c}\text { Kelas } \\
\text { Kontrol }\end{array}$ \\
\hline Jumlah & 648 & 431 \\
\hline $\mathrm{N}$ & 32 & 32 \\
\hline $\bar{X}$ & 20,25 & 13,47 \\
\hline Varians $\left(\mathrm{S}^{2}\right)$ & 46,45 & 25,81 \\
\hline $\begin{array}{c}\text { Standar Deviasi } \\
(\mathrm{S})\end{array}$ & 6,82 & 5,08 \\
\hline
\end{tabular}

Berdasarkan tabel 1 di atas, dengan $\mathrm{N}=32$ diperoleh mean kelas eksperimen sebesar 20,25 dan mean kelas kontrol sebesar 13,47. Artinya kelas eksperimen lebih tinggi kemampuan representasinya dibandingkan dengan kelas kontrol. Standar deviasi kelas eksperimen sebesar 6,82, sedangkan standar deviasi kelas kontrol sebesar 5,08.

Untuk menguji hipotesis terdapat pengaruh yang signifikan penggunaan pembelajaran matematika realistik terhadap kemampuan representasi matematis siswa digunakan uji-t. Hipotesis yang digunakan adalah hipotesis nihil $\left(\mathrm{H}_{0}\right)$ yaitu tidak ada perbedaan kemampuan representasi matematis siswa yang menggunakan pembelajaran matematika realisitik dengan pembelajaran konvensional. $\mathrm{H}_{0}$ diterima apabila nilai $\mathrm{t}$ hitung $>\mathrm{t}$ tabel dengan taraf signifikansi $5 \%$ dan $\mathrm{dk}=62 . \mathrm{H}_{1}$ yaitu ada perbedaan kemampuan representasi matematis siswa yang menggunakan pembelajaran matematika realisitik dengan pembelajaran konvensional. $\mathrm{H}_{1}$ diterima apabila nilai $t_{\text {hitung }}<t_{\text {tabel }}$ dengan taraf signifikansi $5 \%$ dan $\mathrm{dk}=62$.

Setelah dilakukan perhitungan uji-t diperoleh nilai t hitung sebesar 5,28. Sedangkan t tabel dengan taraf signifikansi $5 \%$ dan $\mathrm{dk}=62$ diperoleh 1,67. Maka $\mathrm{t}$ tabel > t hitung sehingga $\mathrm{H}_{0}$ ditolak dan $\mathrm{H}_{1}$ diterima. Dengan demikian berarti terdapat perbedaan kemampuan representasi matematis siswa yang menggunakan pembelajaran matematika realistik dengan yang menggunakan pembelajaran konvensional.

Kemampuan Komunikasi Matematis. Hasil uji normalitas kelas eksperimen matematis, diperoleh $\chi_{\text {hitung }}^{2}(4,0667)<\chi_{\text {tabel }}^{2}(11,07) \quad$ yang berarti data tersebut berdistribusi normal. Pada kelas kontrol juga berdistribusi normal dengan $\chi^{2}$ hitung $(5,4122)<\chi^{2}$ tabel $(11,07)$. Untuk uji homogenitas diperoleh $F_{\text {hitung }}(1,024) \leq F_{\text {tabel }}(1,822)$, artinya data yang diperoleh variansinya homogen..

Berikut ini akan disajikan tabel sumber data kemampuan komunikasi matematis siswa.

Tabel 2: Sumber Data Kemampuan Komunikasi

\begin{tabular}{|c|c|c|}
\hline Sumber variasi & $\begin{array}{c}\text { Kelas } \\
\text { Eksperimen }\end{array}$ & $\begin{array}{c}\text { Kelas } \\
\text { Kontrol }\end{array}$ \\
\hline Jumlah & 417 & 276 \\
\hline $\mathrm{N}$ & 32 & 32 \\
\hline $\bar{X}$ & 13,03 & 8,625 \\
\hline Varians $\left(\mathrm{S}^{2}\right)$ & 7,58 & 7,40 \\
\hline $\begin{array}{c}\text { Standar Deviasi } \\
(\mathrm{S})\end{array}$ & 2,75 & 2,72 \\
\hline
\end{tabular}

Berdasarkan tabel 2 di atas, dengan $\mathrm{N}=32$ diperoleh mean kelas eksperimen sebesar 13,03 dan mean kelas kontrol sebesar 8,625. Artinya kelas eksperimen lebih tinggi kemampuan komunikasinya dibandingkan dengan kelas kontrol. Standar deviasi 
kelas eksperimen sebesar 7,58, sedangkan standar deviasi kelas kontrol sebesar 7,40.

Untuk menguji hipotesis terdapat pengaruh yang signifikan penggunaan pembelajaran matematika realistik terhadap kemampuan komunikasi matematis siswa digunakan uji-t. Hipotesis yang digunakan adalah hipotesis nihil $\left(\mathrm{H}_{0}\right)$ yaitu tidak ada perbedaan kemampuan komunikasi matematis siswa yang menggunakan pembelajaran matematika realisitik dengan pembelajaran konvensional. $\mathrm{H}_{0}$ diterima apabila nilai $t_{\text {hitung }}>t_{\text {tabel }}$ dengan taraf signifikansi $5 \%$ dan $\mathrm{dk}=62 . \mathrm{H}_{1}$ yaitu ada perbedaan kemampuan komunikasi matematis siswa yang menggunakan pembelajaran matematika realisitik dengan pembelajaran konvensional. $\mathrm{H}_{1}$ diterima apabila nilai $t_{\text {hitung }}<t_{\text {tabel }}$ dengan taraf signifikansi $5 \%$ dan $\mathrm{dk}=62$.

Setelah dilakukan perhitungan uji-t diperoleh nilai $t_{\text {hitung }}$ sebesar 6,48. Sedangkan $t_{\text {tabel }}$ dengan taraf signifikansi $5 \%$ dan $\mathrm{dk}=62$ diperoleh 1,67. Maka $t_{\text {tabel }}>t_{\text {hitung }}$ sehingga $\mathrm{H}_{0}$ ditolak dan $\mathrm{H}_{1}$ diterima. Dengan demikian berarti terdapat perbedaan kemampuan komunikasi matematis siswa yang menggunakan pembelajaran matematika realistik dengan yang menggunakan pembelajaran konvensional.

\section{PEMBAHASAN}

Kemampuan Representasi Matematis. Hasil analisis rata-rata data tes kemampuan representasi matematis siswa kelas kontrol menunjukkan angka 13,47, sedangkan siswa kelas eksperimen menunjukkan angka 20,25. Hal ini menyatakan bahwa kelas kontrol dan kelas eksperimen memiliki perbedaan yang signifikan. Ditunjukkan pula dengan hasil uji t yang menunjukkan $t_{\text {hitung }}(5,28)>t_{\text {tabel }}(1,67)$ Sehingga dapat disimpulkan bahwa terdapat perbedaan kemampuan representasi matematis siswa kelas kontrol dan kelas eksperimen, dalam hal ini siswa kelas eksperimen (yang menggunakan pembelajaran matematika realistik) lebih baik kemampuannya dibandingkan kelas kontrol (yang menggunakan pembelajaran konvensional).

Kemampuan Komunikasi Matematis. Hasil analisis rata-rata data tes kemampuan komunikasi matematis siswa kelas kontrol menunjukkan angka 8,625, sedangkan siswa kelas eksperimen menunjukkan angka 13,03. Hal ini menyatakan bahwa kelas kontrol dan kelas eksperimen memiliki perbedaan yang signifikan. Ditunjukkan pula dengan hasil uji t yang menunjukkan $t_{\text {hitung }}(6,43)>t_{\text {tabel }}(1,67)$. Sehingga dapat disimpulkan bahwa terdapat perbedaan kemampuan komunikasi matematis siswa kelas kontrol dan kelas eksperimen, dalam hal ini siswa kelas eksperimen (yang menggunakan pembelajaran matematika realistik) lebih baik kemampuannya dibandingkan kelas kontrol (yang menggunakan pembelajaran konvensional).

Siswa yang sudah mempunyai kemampuan pemahaman matematis dituntut juga untuk bisa mengomunikasikannya, agar pemahamannya bisa dimanfaatkan oleh orang lain. Dengan kemampuan komunikasi matematis siswa juga bisa memanfaatkan konsep-konsep matematika yang sudah dipahami orang lain. Dengan mengomunikasikan ide-ide matematisnya kepada orang lain, seseorang bisa meningkatkan pemahaman matematisnya. Sedangkan representasi sendiri merupakan salah satu kunci keterampilan komunikasi matematis. Representasi merupakan penggambaran, penerjemahan, pengungkapan, penunjukkan kembali, pelambangan, atau pemodelan, gagasan konsep dalam matematika, dan hubungan diantaranya yang termasuk dalam suatu konfigurasi, konstruksi, atau situasi tertentu yang ditampilkan siswa dalam berbagai bentuk sebagai upaya memperoleh 
kejelasan makna, menunjukkan pemahamannya atau mencari solusi dari masalah yang dihadapinya.

Pendidikan matematika realistik memiliki lima karakteristik. yakni, menggunakan masalah kontekstual (the use of context): proses pembelajaran diawali dengan masalah kontekstual yang dikenal, menggunakan instrumen vertikal (bridging by vertical instruments): penggunaan instrumen-instrumen vertikal berupa model, skema, diagram ataupun simbol sebagai jembatan antara prosedur informal dengan bentuk formal, kontribusi siswa (student contribution): siswa aktif mengkostruksi sendiri bahan matematika strategi pemecahan masalah dengan bimbingan guru, kegiatan interaktif (interactivity): siswa diberi kesempatan menyampaikan ide-ide, melakukan negosiasi secara eksplisit, berkolaborasi, dan evaluasi antar sesama siswa, siswa terhadap perangkat belajar, dan interaksi siswa dengan guru secara konstruktif dan keterkaitan (Intertwining): dalam matematika, struktur dan konsep saling terkait. Beberapa diantaranya adalah kegiatan interaktif. Siswa diberi kesempatan menyampaikan ide-ide dan berdiskusi sesama siswa serta interaksi dengan guru yang dapat mengasah kemampuan komunikasi matematis siswa. Selain itu PMR menggunakan instrumen vertikal berupa model, skema, diagram ataupun simbol. Hal itu dapat diartikan sebagai penerjemahan suatu masalah dalam bentuk matematis berupa gambar, simbol maupun persamaan matematis yang mana hal ini merupakan bentuk dari representasi eksternal.

\section{PENUTUP}

\section{Simpulan}

Berdasarkan hasil penelitian dan pembahasan, dapat disimpulkan bahwa pembelajaran matematika realistik berpengaruh terhadap kemampuan representasi dan komunikasi matematis siswa. Kemampuan representasi dan komunikasi matematis siswa yang menggunakan pembelajaran matematika realistik lebih tinggi daripada siswa yang menggunakan pembelajaran konvensional.

\section{Saran}

Berdasarkan temuan penelitian ini, peneliti menyarankan sebagai berikut:

1. Bagi guru; Pembelajaran dengan pendekatan pembelajaran matematika realistik cukup baik dalam meningkatkan kemampuan representasi dan komunikasi matematis siswa sehingga dapat dijadikan alternatif dalam proses pembelajaran; Hendaknya dapat menambah wawasan untuk dapat menambahkan alat peraga atau media pembelajaran untuk lebih membantu dalam pembelajaran.

2. Bagi sekolah diharapkan dapat mendukung dan menyediakan alat peraga atau pelatihan guru yang berkaitan dengan pendekatan pembelajaran matematika realistik.

3. Bagi peneliti selanjutnya, penelitian ini dapat dilanjutkan dengan meneliti pada indikator kemampuan matematika yang lain seperti penalaran matematis, kemampuan pemecahan masalah matematis dan lain-lain, dan pada jenjang pendidikan yang lain.

\section{DAFTAR PUSTAKA}

Aditya, Arif. 2014. Pendekatan Realistic Mathematics Education untuk Meningkatkan Kemampuan Representasi Matematis Siswa Kelas VIII SMPIT Ruhama Depok. Skripsi: Universitas Islam Negeri Syarif Hidayatullah Jakarta.

Baroroh. 2010. Penerapan Pembelajaran Matematika dengan Pembelajaran Matematika Realistik untuk Melatih Berpikir Kreatif Siswa. Skripsi: Universitas Islam Negeri Sunan Ampel Surabaya.

Pranoto. 2012. UN Menyiapkan Anak Menjadi Kuli Nirnalar. http://www.slideshare.net/y0r/un- 
Hidayatul Purnama Ariyanti : Pengaruh Pembelajaran Matematika Realistik Terhadap Kemampuan Matematis Siswa (Ditinjau Dari Kemampuan Representasi Dan Komunikasi)

matematika-menyiapkan-anak-menjadi-kuli-

nirnalar. Diakses tanggal 5 Agustus 2015.

Rima. 2014. PISA 2012: Siswa Indonesia Miskin Kemampuan Bernalar.

blogs.itb.ac.id/appledore/2014/02/18/32/.

Diakses tanggal 5 Juli 2015.

Simanjuntak, Maslina. 2014. Peningkatan Kemampuan

Representasi dan Komunikasi Matematis Siswa pada Materi Transformasi dengan Strategi TTWW Berbantu Kartu Domino Kelas VII SMP Negeri 3 Tebing Tinggi. Tesis: Universitas Negeri Medan. 